Volume 10, No 2, julho-dezembro 2014, Jataí-GO | ISSN: 1807-9342 DOI: 10.5216/rir.v10i2.32502 
Revista Itinerarius Reflectionis - UFG.

Volume 10, No 2, julho-dezembro 2014, Jataí-GO.

Semestral.

ISSN: $1807-9342$

\section{Universidade Federal de Goiás}

\section{Reitor}

Orlando Afonso Valle do Amaral

\section{Vice-Reitor}

Manoel Rodrigues Chaves

Pró-Reitoria de Graduação

Luiz Mello de Almeida Neto

\section{Regional Jataí}

Diretor: Wagner Gouvêa dos Santos

\section{Editores Responsáveis}

Eveline Borges Vilela-Ribeiro

José Sílvio Oliveira

Vânia Ramos Rodrigues 


\section{Sumário}

Relaçóes raciais no núcleo de estudos de gênero, raça e idade (NEGRI) : um balanço inicial (1992-2014) .........................................5

Introdução

A produção do negri (teses e dissertaçóes) ..........................................13

Metodologia do negri.................................................................................18

Análise quantitativa da produçáo do negri..........................................20

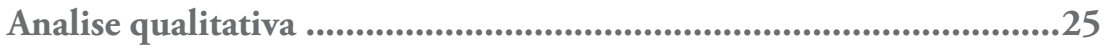

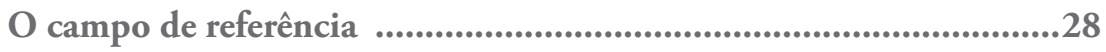

O período abrangido ......................................................................29

O objeto em enfoque ..................................................................................32

Referências ...................................................................................................34 


\title{
RELAÇŌES RACIAIS NO NÚCLEO DE ESTUDOS DE GÊNERO, RAÇA E IDADE (NEGRI) : UM BALANÇO INICIAL (1992-2014)
}

\author{
Marcos Antonio Batista da Silva \\ marcos.psico@yahoo.com.br \\ PUC-SP
}

\section{Resumo}

Este artigo faz um balanço inicial das teses e dissertaçóes defendidas no contexto do NEGRI do Programa Pós-graduados em Psicologia Social da PUC-SP no período entre (19922014) referente as relaçóes raciais. $O$ fato de que a desigualdade e a pobreza têm cor no Brasil faz com que nossas políticas sociais, supostamente universais, terminem por obter resultados insuficientes, na medida em que não contribuem para a superação dessa ordem de desigualdade.

Palavras-chave: relaçóes raciais; negros na educação; pesquisadores negros ; desigualdades educacionais.

Race relations at the center for the study of gender, race and age (NEGRI): an initial balance (1992-2014)

\section{Abstract}

This article makes an initial balance of theses and dissertations in the context of the Negri Postgraduates in Social Psychology from PUC-SP program in the period (1992-2014) regarding race relations. The fact that inequality and poverty in Brazil have color makes our supposedly universal social policies finish by obtaining insufficient results, insofar as they do not contribute to overcoming this order of inequality.

Keywords: race relations; blacks in education; black researchers; educational inequalities 
Vol. 10, № 2, julho-dezembro 2014 


\section{Introdução}

$\mathrm{O}$ presente artigo propõe um balanço inicial da produção (teses e dissertaçóes) do NEGRI do Programa de Estudos Pós-Graduados em Psicologia Social da Pontifícia Universidade Católica de São Paulo (PUC-SP). O NEGRI foi coordenado pela professora Fúlvia Rosemberg, que orientava pesquisadores(as) negros(as) e brancos(as) no que se ferere a temas como o das relações raciais em conexão com as desiguladades de idade (crianças, adolescentes e adultos) e gênero, no contexto da educação brasileira. Para tanto, encontramos respaldo em Rosemberg (2001), o qual esclarece o papel da pesquisa na elaboração e avaliação de políticas públicas: instrumentalizar atores sociais, especialmente os alijados de posiçóes vantajosas, para participarem de negociaçóes com o maior acervo de conhecimento possível. Configura-se, assim, pois, um compromisso ético e político da pesquisa.

Minha participação neste campo sobre relações étnico-raciais se deve a duas razóes principais: primeiramente, desde 2012, venho pesquisando trajetórias educacionais de mestres (as) negros (as) paulistas, da ótica de raça, racismo e desigualdades educacionais, na linha de pesquisa "Aportes da Psicologia Social à compreensão de problemas sociais", no contexto do NEGRI. Minha decisão de trilhar conscientemente esse caminho intelectual foi sempre uma opção excepcional e difícil.

Segundo, me autodeclaro negro, conscientizando-me como negro e pós-graduando, penso ser importante conhecer e divulgar estudos realizados por pesquisadores negros e brancos, homens e mulheres sobre a temática das relaçôes raciais no Brasil. Sempre almejei estudar em uma grande universidade, mas a falta de condiçôes materiais nos distanciava dos perfis privilegiados pelas políticas e programas de pós-graduação no país.

Ao ingressar no Programa de Estudos Pós-Graduados em Psicologia Social da PUC/SP, no ano de 2012, e concretizando parcialmente nossos objetivos, representávamos algo raro nas famílias negras brasileiras, o filho 
doutorando. $\mathrm{O}$ ingresso na pós-graduação pode repercutir socialmente, alterando o meio social em que se circula. "A universidade é o divisor de águas numa sociedade racialmente dividida [...] até existir uma classe média negra profissional, com domínio dos mesmos códigos e competências da elite, não haverá combate efetivo à discriminação racial” (BROOKE, 2002, p.154-155).

O fato de que a desigualdade e a pobreza têm cor no Brasil faz com que nossas políticas sociais, supostamente universais, terminem por obter resultados insuficientes, na medida em que não contribuem para a superação dessa ordem de desigualdade. Temos crescimento econômico, científico e tecnológico. Porém, as desigualdades sociais continuam sendo uma marca da sociedade brasileira. Assim, por exemplo, no Plano Nacional de Pós-Graduação (PNPG) 2011-2010 (p. 39) só encontramos uma referência sobre a questão étnico-racial. Conforme o documento, "constatase uma grande desigualdade quando a comparação é feita levando-se em consideração alguns fatores como a questão regional, o pertencimento étnico, o gênero, a sexualidade, a condição social, entre outros". Entende-se que essas situaçốes de desigualdade racial decorrem de uma matriz histórica que pode ser expressa ao revisitarmos a literatura sobre relaçóes raciais no Brasil.

Vale ressaltar que a Lei no 13.005 , de 25 junho de 2014, aprovou o Plano Nacional de Educação - PNE (2011-2020). Cinco das 20 metas do novo PNE tratam especificamente de atividades da Educação Superior. No que se refere à questão étnico-racial no (PNE 2011-2020), a meta 8, propóe elevar a escolaridade média da população de dezoito a vinte e quatro anos de modo a alcançar o mínimo de doze anos de estudo para as populaçóes do campo, da região de menor escolaridade no país e dos $25 \%$ mais pobres, bem como igualar a escolaridade média entre negros e não negros, com vistas à redução da desigualdade educacional. Tais metas mostram que os desafios para a Educação Superior são expressivos e vão exigir um plano de 
articulação bem elaborado entre governos e instituiçóes formadoras, para que possam ser efetivamente alcançadas.

Vivemos, pois, um momento ímpar da agenda das políticas educacionais pela introdução de um novo tema: políticas de ação afirmativa na educação. Em décadas passadas, a grande maioria dos estudos discutia a trajetória do negro antes de chegar à graduação, hoje já discutimos a mobilidade educacional do negro.

Os estudos sobre relaçôes raciais no Brasil contemporâneo têm se desenvolvido, nas últimas décadas, devido ao impulso de uma série de iniciativas nacionais e internacionais. A exemplo, no âmbito internacional, a "I Conferência Mundial contra o Racismo, a discriminação racial, xenofobia e as formas conexas de intolerância” realizada em 2001, que contou com a participação do Brasil e de mais de 172 países, “4 mil organizaçóes não governamentais (ONGs) e um total de mais de 16 mil participantes" (SILVA, 2014, p.38).

No cenário nacional, merecem destaque: a criação da Secretaria de Políticas de Promoção da Igualdade Racial (SEPPIR), em 2003, e o Estatuto da Igualdade Racial, aprovado pela Presidência da República em 2013. Observa-se, ainda, o desenvolvimento de programas de valorização da cultura e da história negra.

A extensa e periódica divulgação de indicadores socioeconômicos, sob responsabilidade de Instituiçóes de estatística e de pesquisa como o Instituto Brasileiro de Geografia e Estatística (IBGE), o Instituto de Pesquisa Econômica Aplicada (IPEA), o Departamento Intersindical de Estatística e Estudos Socioeconômicos (DIESE) ou o Fundo de Desenvolvimento das Naçôes Unidas para a Mulher (UNIFEM), mostram que grandes diferenciais raciais marcam praticamente todos os campos da vida social brasileira; no que diz respeito à saúde, renda, acesso a empregos, violência, expectativa de vida e educação, essa última, nosso foco de atenção. 
A síntese dos estudos ${ }^{1}$ que iremos apresentar permite, a partir de um recorte temporal definido (1992-2014), conhecer e sistematizar a produçáo de conhecimento, identificar temáticas e abordagens, verificar lacunas e campos até então inexplorados. Trata-se de uma bibliografia em expansão no país, atestada pelos indicadores da produção acadêmica: número de teses e dissertaçóes defendidas e número de publicaçóes. Focalizamos para este artigo as pesquisas realizadas pelo NEGRI (BENTO, 1992; OLIVERIA, 1992; MORO 1993; OLIVEIRA, 1994; PIZA, 1995; BAZILLI, 1999; ROCHA, 2005; SILVA, 2005; FERREIRA, 2010; SILVA, 2014).

Esses pesquisadores ${ }^{2}$ adotam uma concepção de raça, da perspectiva de Rosemberg e colaboradores (2003), Guimarães (2002), entendendo "raça" como uma construção social e um conceito analítico fundamental para a compreensão de desigualdades socioestruturais e simbólicas observadas na sociedade brasileira. Portanto, o sentido atribuído ao termo raça não é aquele da biologia, sentido, mas que permanece vivo no senso comum para classificar hierarquicamente segmentos sociais. O debate conceitual sobre os conceitos raça e etnia é intenso, tanto no Brasil, quanto no exterior. Entendemos que certas discriminaçóes são subjetivamente justificadas ou inteligíveis somente pela ideia de raça, que é usada para classificar e hierarquizar pessoas e segmentos sociais. $\mathrm{O}$ uso do conceito de raça, como uma construção social, ajuda a atribuir realidade social à discriminação e, consequentemente, a lutar contra ela. $\mathrm{O}$ uso do conceito de raça ajuda a atribuir realidade social à discriminação e, consequentemente, a lutar contra ela.

1 Vale ressaltar que aos estudos a que nós se referimos são as teses e dissertações defendidas no NEGRI até o mês de outubro de 2014.

2 Para a formação de um pesquisador fazem-se necessários anos de estudos. "O debate sobre modelos de formação pós-graduada tem sido, por sua vez, um dos temas centrais em discussões que envolvem esse nível de ensino, talvez até como corolário de sua expansão e consolidação" (VELLOSO, 2004, p. 3). Uma particularidade da sociedade brasileira é que a formação e a prática em pesquisa ocorrem, quase que exclusivamente, no âmbito da pós-graduaçáo (GUIMARÃES et al, 2001; VELOSSO, 2004; VELHO, 2007). 
No que se refere ao racismo, adotam uma concepção que integra as dimensôes estrutural e simbólica na compreensão da produção e reprodução das desigualdades raciais, fundamentos em (ESSED, 1991; ROSEMBERG, 2003; GUIMARÁES, 2005). Isto porque no plano simbólico, o racismo manifesta-se na aceitação da crença da superioridade, entendida como natural, de um grupo racial sobre outro. No plano estrutural, os diferentes segmentos raciais têm, sistematicamente, acesso desigual a bens materiais e não materiais.

Para eles, e para nós, tais desigualdades não são explicadas apenas pelo preconceito, pelos estereótipos ou por outras atitudes ou crenças individuais, mas também por uma estrutura de relações de poder sistematicamente assimétrica entre os segmentos étnico-raciais. Assim, os estudos sobre relaçóes raciais no contexto do NEGRI, indicados no quadro 1 buscam compreender os eixos de desigualdade de gênero, raça e idade, bem como apreender "as maneiras como as formas simbólicas se entrecruzam com relações de poder" (Thompson,2011,p.75).

\section{Quadro 1- Teses e dissertaçóes defendidas sobre relaçóes raciais do}

NEGRI (1992-2010)

\begin{tabular}{l|l|l|l} 
Autor & $\begin{array}{l}\text { Natureza do } \\
\text { trabalho }\end{array}$ & Ano & Título \\
$\begin{array}{l}\text { Maria Aparecida } \\
\text { Silva Bento }\end{array}$ & Dissertação & 1992 & $\begin{array}{l}\text { Resgatando a minha bisavó: discriminação } \\
\text { racial no trabalho e resistência na voz dos } \\
\text { trabalhadores negros. }\end{array}$ \\
\hline $\begin{array}{l}\text { Rachel de } \\
\text { Oliveira }\end{array}$ & Dissertação & 1992 & $\begin{array}{l}\text { Relaçóes raciais na escola: uma experiência de } \\
\text { intervenção. }\end{array}$ \\
\hline $\begin{array}{l}\text { Neiva de } \\
\text { Oliveira Moro }\end{array}$ & Dissertação & 1993 & $\begin{array}{l}\text { Um estudo sobre o universitário do anual } \\
\text { de } 1990 \text { da Universidade Estadual de Ponta } \\
\text { Grossa: carreiras educacionais e raças. }\end{array}$ \\
\hline Eliana Oliveira & Dissertação & 1994 & $\begin{array}{l}\text { Relaçôes raciais nas creches do município de } \\
\text { São Paulo. }\end{array}$ \\
\hline
\end{tabular}




\begin{tabular}{l|l|l|l} 
Autor & $\begin{array}{l}\text { Natureza do } \\
\text { trabalho }\end{array}$ & Ano & Título \\
\hline Edith Piza & Tese & 1995 & $\begin{array}{l}\text { O Caminho das águas: estereótipos de } \\
\text { personagens femininas negras nas obras } \\
\text { femininas de escritoras brancas. }\end{array}$ \\
\hline $\begin{array}{l}\text { Chirley Bazilli } \\
\text { Paulo Vinícius } \\
\text { Baptista da Silva }\end{array}$ & Tese & 2005 & $\begin{array}{l}\text { Discriminaçóes contra personagens negros } \\
\text { na literatura infantojuvenil brasileira } \\
\text { contemporânea. }\end{array}$ \\
\hline $\begin{array}{l}\text { Edmar José } \\
\text { Rocha }\end{array}$ & Dissertaçáa raciais em livros didáticos de língua \\
\hline $\begin{array}{l}\text { Antônio } \\
\text { Honório Ferreira }\end{array}$ & 2005 & $\begin{array}{l}\text { Autodeclaração de cor e/ou raça entre alunos/ } \\
\text { as paulistanos/as do ensino fundamental e } \\
\text { médio: um estudo exploratório. }\end{array}$ \\
\hline $\begin{array}{l}\text { Marta Lúcia da } \\
\text { Silva }\end{array}$ & Dissertaçáo & 2014 & $\begin{array}{l}\text { Discursos de mães negras sobre educação e } \\
\text { cuidado de crianças de até três anos de idade. }\end{array}$ \\
\hline
\end{tabular}

Fonte: Plataforma Lattes/ Currículo Lattes

Essas teses e dissertaçóes defendidas, relacionadas à população negra (crianças, adolescentes e adultos), especificam, particularmente, aspectos da educação por níveis: educação infantil, ensino fundamental, ensino médio e educação superior (graduação e pós-graduação), além de apresentar investigaçóes que se referem a programas de ação afirmativa e sobre discriminação racial e desigualdades no mercado de trabalho e sua superação. Outras investigaçóes estão relacionadas ao racismo discursivo em diferentes meios: literatura, literatura infanto-juvenil, livros didáticos. Assim, este estudo compartilha com os trabalhos supracitados no que diz respeito a uma meta política, ou seja, a do enfrentamento das desigualdades raciais no sistema educacional brasileiro. 


\section{A produção do negri (teses e dissertaçóes)}

A dissertação de Bento (1992), centrada nos trabalhadores negros, procurou captar e desvelar práticas discriminatórias que atingem a população negra $^{3}$ economicamente ativa nas relaçóes de trabalho e as reaçóes então decorrentes, de modo a tornar visíveis as experiências de discriminação racial e resistência negra no mercado de trabalho. Esse estudo chamou a atenção para as dimensões relacionais da discriminação, identificando a persistência e continuidade da ação discriminatória branca e da resistência negra.

Por sua vez a dissertação de Oliveira (1992) relatou uma experiência de intervenção educacional realizada por um grupo de professores negros da rede pública de ensino do estado de São Paulo na década de 1980. Dentre os trabalhos realizados por esse grupo, destacou-se a implantação de um projeto intitulado "Salve 13 de maio", que foi o instrumento que deflagrou, dentro das escolas, o processo de debate sobre a situação socioeconômica e política do negro brasileiro. A resposta dos participantes do debate ao questionamento do grupo tornou-se uma rica fonte de informação para a análise do pensamento da escola sobre o negro. A autora em sua pesquisa procurou desvelar as formas de preconceitos vigentes na instituição escolar. $\mathrm{O}$ resultado desse trabalho forneceu novas pistas de análise sobre escolarização e exclusão de alunos negros do sistema de ensino, oferecendo assim, valiosa contribuição para futuros estudos sobre relaçóes raciais na escola no Brasil.

A dissertação de Moro (1993), um dos estudos pioneiros no Brasil sobre educação superior e relaçóes raciais, analisou a inserção de estudantes negros na Universidade Estadual de Ponta Grossa - UEPG, ocupando-se da investigaçáo de suas carreiras educacionais, comparando às dos brancos. Os resultados apontaram para a responsabilidade da universidade, não apenas

3 Sugestão de leitura: PAIXÃO, Marcelo (Org). Relatório Anual das Desigualdades Raciais no Brasil: 2009-2010, UERJ, 2010. 
na oferta de cursos, mas, principalmente, com relação à atenção dada às situações objetivas do meio social dos alunos.

Em outra dissertação, Oliveira (1994) procurou estimar a composição racial de crianças que frequentavam as creches do município de São Paulo, utilizando-se da heteroatribuição ${ }^{4}$ de cor/raça (classificação, mediante a apresentação de fotos dessas crianças). Para discutir a dinâmica das relações raciais nas creches, a autora efetuou a análise de documentos e realizou entrevistas com profissionais das creches e técnicos da administração central. A análise foi amparada pela produção, reflexôes e práticas que tematizaram as relaçóes raciais no plano da política municipal. O estudo de Oliveira chamou a atenção para evidências racialmente discriminatórias no plano das políticas e das relaçóes interpessoais nas creches. As educadoras de creche do município de São Paulo tendiam a classificar a cor de crianças fotografadas em maior consonância com sua própria autodeclaração. Assim, de um modo geral, as sofisticadas e complexas análises de que dispomos sobre processo classificatório de cor/raça no Brasil se referem, preferencialmente, ao mundo adulto.

A tese de Piza (1995) procurou compreender a construção do estereótipo da personagem feminina negra sexualizada presente na literatura infanto-juvenil brasileira produzida por quatro escritoras brancas realistas, que produziram seus textos entre os anos 1970 e o final dos anos 1980. A autora constata mudanças temáticas na literatura infanto-juvenil brasileira nesse período, mais especificamente nas alteraçóes dos estereótipos de crianças, mulheres brancas e negras que essa literatura vinha reproduzindo. Piza (1995) apreendeu que os estereótipos não devem ser vistos apenas como preconceitos irracionais e inválidos. No nível das imagens, a sexualidade da mulher negra pode expressar uma metáfora da criação literária em momentos

4 Sugestão de leitura: CARVALHO, Marília Pinto de. O fracasso escolar de meninos e meninas: articulaçôes entre gênero e cor/raça. Cad. Pagu, Campinas, n. 22, June 2004. PETRUCCELLI, J. L., SABOIA, A. L. (Org). Características étnico-raciais da população: classificaçôes e identidades. R.J. IBGE, 2013. 
especcíficos da trajetória das autoras. A pesquisa apontou para uma não sincronia: de um lado a introdução de um tema que era tabu (sexualidade em literatura para jovens) e de outro a manutenção de estereótipos racistas (a sexualidade associada à mulher negra).

Por sua vez, a dissertação de Bazilli (1999), outro trabalho que integra a produção dos estudos das discriminaçóes raciais de personagens negros na literatura infanto-juvenil brasileira, publicada entre os anos 1975 e 1994. Bazilli (1999) focalizou as discriminaçóes contra personagens negros e constatou a tendência à representaçáo ficcional de personagens brancos, adultos e do sexo masculino, como representantes da espécie, assim como a representação de personagens negros tipificados. Esse estudo partiu de uma ampla pesquisa coletiva que visara atualização de pesquisa similar, coordenada por Fúlvia Rosemberg em 1975, ao analisar livros infanto-juvenis. Bazilli (1995) apreendeu que poucas foram às transformaçóes que ocorreram nos vinte anos que separaram ambas as pesquisas: alteração no gênero literário; redução de livros históricos e a maior presença de indivíduos humanos. A grande tendência observada pela pesquisa do período anterior (1975), a de representar ficcionalmente personagens brancos, adultos e de sexo masculino como "representantes da espécie" continua vigorando, assim como de representar personagens negros tipificados, porém de forma mais sutil. É o que a Bazilli chamou de reacomodação da dinâmica racista.

A tese de Silva (2005) efetuou análise de discursos sobre os segmentos raciais negros e brancos em livros didáticos de Língua Portuguesa para a quarta série do ensino fundamental, publicados entre os anos 1975 e 2004. $\mathrm{O}$ autor procurou examinar os possíveis impactos da movimentação em torno do tema na produção de discursos racistas em livros didáticos de Língua Portuguesa, procurando apreender permanências e mudanças dos discursos no período considerado, adotando, para tanto, uma perspectiva diacrônica. A análise do contexto de produção dos livros didáticos de Língua Portuguesa e a análise formal permitiram ao autor, desenvolver a tese de que, a despeito de toda a movimentação no campo de produção 
dos livros didáticos, de o tema racimo nos livros didáticos ter participado da agenda das políticas educacionais brasileiras, das avaliaçóes promovidas pelo Ministério da Educação/MEC, o livro didático continuou produzindo e veiculando um discurso racista.

Quase uma década após a investigação de Silva (2005), destacamos a pesquisa recentemente concluída por Ribeiro ${ }^{5}$ (2013) e desenvolvida no NEGRI sobre livros didáticos: "Relaçóes de gênero e de idade em discursos sobre sexualidade veiculados em livros didáticos brasileiros de Ciências Naturais". Esse estudo se diferenciou do estudo de Silva ao analisar, nos livros didáticos destinados ao Ensino Fundamental II, relaçóes de gênero e de idade, indicando os modos utilizados por essas mídias para a permanência de valores normativos que geram e sustentam relaçôes assimétricas. Confirma-se, por meio da análise realizada pela autora, que as assimetrias de idade, assim como as de gênero, de cor/raça se mantem nos discursos proferidos nos livros analisados. Isso se dá pelos elementos que estruturam o conteúdo (imagens e textos) e por meio da estratégia ideológica que universaliza e estigmatiza a supremacia adulta, branca, heterossexual (RIBEIRO, 2013).

Outra produção importante se refere à dissertação de Rocha (2005). Esse estudo focalizou o tema da classificaçáo racial ao explorar a autoclassificação de cor e/ou raça entre crianças e adolescentes, alunos de escolas públicas da cidade de Sáo Paulo. Vale destacar que o debate sobre classificação racial no Brasil tem merecido atenção de pesquisadores ao longo das últimas décadas, tais como Munanga (2003), Guimarães (2005), Petrucelli (2007), entre outros. Esse tema continua ganhando visibilidade pública em decorrência dos Programas de ação afirmativa, com mobilização favorável e contrária às cotas. Rocha (2005) verficou se as crianças e os adolescentes respondiam de modo equivalente quando perguntadas "qual a sua cor?”, "qual a sua cor/raça?". Ao problematizar o tema, o autor conclui

5 Sugestáo de leitura: RIBEIRO, M. S. Relaçóes de gênero e de idade em discursos sobre sexualidade veiculados em livros didáticos brasileiros de Ciências Naturais. São Paulo: PUC-SP, (dissertação de mestrado), 2013. 
que em relação ao silêncio que impregna as relaçôes raciais na escola, as crianças e os adolescentes dispóem de competência para expressarem, eles mesmos, sua pertença racial.

A tese de Ferreira (2010), por sua vez, ofereceu importante colaboração para a compreensão e a melhoria da prática de processos de identificação étnico-raciais em experiência de ação afirmativa. Seu objetivo específico foi descrever e propor interpretaçóes de discursos étnico-raciais proferidos no contexto do Programa Internacional de Bolsas de Pós-graduação da Fundação Ford ${ }^{6}$ (Programa IFP). Esse estudo articula-se à perspectiva do NEGRI, propondo pensar a ação afirmativa como uma das estratégias, mas não a única de combate à desigualdade racial brasileira ao apresentar interpretaçóes a discursos étnico-raciais, proferidos no contexto de Programa de ação afirmativa destinado, entre outros segmentos sociais, aos negros e indígenas.

Ferreira (2010) observa uma grande diversidade de discursos, quando se analisam relatos raciais, inclusive no interior de subconjuntos específicos de pessoas que se autodeclaram de mesma cor/raça. Isso indica uma complexificação da operacionalização de Programas de açóes afirmativas que tenham como foco a justiça social e não a diversidade. A relevância social da tese de Ferreira (2010), por um lado, é ter procurado adentrar na complexidade do processo de classificação/identificação racial em experiência brasileira de ação afirmativa. E, por outro, mostrar uma preocupação recente no contexto dos estudos sobre relaçóes raciais no Brasil: políticas de ação afirmativa. De modo geral, antes da implantação de

6 O sítio oficial do Programa informa que a Fundação Ford é uma organização de caráter privado, sem fins lucrativos, que foi criada nos Estados Unidos da América para ser uma fonte de apoio a pessoas e instituiçóes inovadoras em todo mundo, comprometidas com a consolidação da democracia, a reduçáo da pobreza e da injustiça social e o desenvolvimento humano, cf. Ferreira, 2010; e www. programabolsa.org.br. O programa de bolsas de pesquisa, com enfoque nas açôes afirmativas, coordenado pela Fundaçáo Carlos Chagas no Brasil, nos deram uma amostra significativa da existência da grande demanda reprimida por educação de grupos subrepresentados no país, como negros e indígenas. 
políticas de ação afirmativa ${ }^{7}$, o foco das pesquisas sobre relações raciais, no que tange às desigualdades educacionais, estava voltado para a discussão das dificuldades e obstáculos enfrentados pelo negro para chegar à graduação, hoje já discutimos a mobilidade educacional do negro.

Por fim focalizamos a recente dissertação de Silva (2014) dando sequência a outros trabalhos do NEGRI no que se refere ao processo de construção social da infância no Brasil (investigando a invisibilidade do bebê e problematizando as políticas públicas referentes à educação e cuidado no contexto da creche) descreveu e interpretou discursos proferidos por três mulheres negras (pretas), mães de bebês, pertencentes às camadas médias urbanas, residentes no município de São Paulo, sobre educação e cuidado de crianças de até 3 anos de idade. A dissertação de Silva (2014) apoiou-se nos estudos sobre relaçóes raciais no Brasil que propiciam a compreensão das desigualdades raciais e sociais que caracterizam a sociedade brasileira. Para a autora os resultados obtidos foram que os bebês aparecem como sendo um ser em desenvolvimento, dependente de adultos, que necessitam de cuidados mais intensos e específicos. Segundo Silva (2014) a creche pública aparece como opção positiva de educação e cuidado, como um dever do Estado e direito do bebê como cidadão.

\section{Metodologia do negri}

O NEGRI também tem adotado em suas pesquisas o método da hermenêutica de profundidade (HP) - proposta de John B. Thompson em seu livro Ideologia e Cultura Moderna (2011), que propóe "o estudo

7 Decreto $\mathrm{n}^{\circ} 7.284$, de 11/10/2012, regulamenta a Lei $\mathrm{n}^{\circ} 12.711$, de 29 de agosto de 2012, que dispóe sobre o ingresso nas universidades e nas instituiçôes federais de ensino técnico de nível médio. Em cada instituição federal de ensino superior, as vagas de que trata o art. 1o desta Lei serão preenchidas, por curso e turno, por autodeclarados pretos, pardos e indígenas, em proporção no mínimo igual à de pretos, pardos e indígenas na população da unidade da Federaçáo onde está instalada a instituiçáo, segundo o último censo do Instituto Brasileiro de Geografia e Estatística (IBGE). 
da construção e contextualização social das formas simbólicas"(p.363). Thompson (2011) propóe, com sua teoria crítica sobre ideologia, uma metodologia da interpretação voltada para a análise prática das formas simbólicas e da transformação interpretativa da doxa, entendida como "opiniốes, crenças e compreensóes que são partilhadas pelas pessoas que constituem o mundo social" (THOMPSON, 2011).

As formas simbólicas são aqui entendidas como açôes, falas, imagens e textos recebidos, reproduzidos e colocados em circulação. Podem ser de ordem linguística, não linguística ou mista, e devem ser consideradas pelos pares como significativas e reconhecidas em contextos socialmente estruturados. $\mathrm{O}$ autor compreende sua aplicação em três fases: análise sócio-histórica, análise formal ou discursiva e interpretação (ou reinterpretação).

A primeira etapa do enfoque da hermenêutica de profundidade (HP) é a análise sócio - histórica, que tem por objetivo "reconstruir as condições sociais e históricas de produção, circulação e recepção das formas simbólicas"( THOMPSON, 2011, p.366). A análise formal ou discursiva, segunda fase da hermenêutica de profundidade (HP), propóe o estudo das formas simbólicas que circulam nos campos sociais, ou seja, é a análise das características estruturais e das relaçôes do discurso, "uma organização interna das formas simbólicas, com suas características estruturais, seus padrôes e suas relaçóes" (THOMPSON, 2011, p.39). Conforme Thompson (2011) esta fase pode ser realizada por meio de diferentes tipos ou métodos de análise.

No NEGRI, adota-se a "análise de conteúdo", seguindo as orientações Bardin (2011) e Rosemberg (1981) bem como, de recortes temáticos ajustados a cada tipo de discurso. Desse modo, adotamos o conceito de discurso como tem sido amplamente empregado na teoria e análise social, como instâncias de comunicação usuais, que são constitutivas e constituídas nos diferentes modos de estruturação das práticas sociais. Discursos se manifestam em modos particulares de uso das formas simbólicas, em particular da linguagem, e não apenas refletem as relaçóes sociais, mas 
participam de sua construção (THOMPSON, 2011). A última etapa da hermenêutica de profundidade (HP), interpretação e reinterpretação, se constrói a partir das fases anteriores de análise sócio-histórica e análise formal ou discursiva.

\section{Análise quantitativa da produção do negri}

foi realizada uma primeira aproximação com o corpus documental de 10 estudos (teses e dissertaçóes) defendidos pelo NEGRI sobre relaçóes raciais pela via quantitativa, descrevendo sua configuração mediante quadros e tabelas construídas a partir dos seguintes critérios: sexo; produções por sexo e natureza do trabalho acadêmico; produções por subtemas, natureza do trabalho e sexo; produçóes por ano; professores participantes em bancas de defesas e agências financiadoras.

Tabela 1 - Sexo dos pesquisadores

\begin{tabular}{c|c|c} 
Sexo & Quantidade & Percentual \\
\hline Masculino & 3 & $30,0 \%$ \\
\hline Feminino & 7 & $70,0 \%$ \\
\hline Total & 10 & $100 \%$ \\
\hline
\end{tabular}

Fonte: Banco de dados da pesquisa

Tabela 2- Produçóes por sexo e natureza do trabalho acadêmico

\begin{tabular}{c|c|c|c|c} 
Natureza do trabalho & \multicolumn{2}{|c|}{ Mestrado } & \multicolumn{2}{c}{ Doutorado } \\
Sexo & Feminino & Masculino & Feminino & Masculino \\
\hline Quantidade de trabalhos & 6 & 1 & 1 & 2 \\
\hline Percentual por nível & $60,0 \%$ & $10,0 \%$ & $10,0 \%$ & $20,0 \%$ \\
\hline
\end{tabular}

Fonte: Banco de dados da pesquisa

Tabela- 3 Produçóes por subtema, natureza do trabalho e sexo

\begin{tabular}{l|c|c|c|c}
\multirow{2}{*}{ Subtemas } & \multicolumn{2}{|c|}{ Natureza do trabalho } & \multicolumn{2}{c}{ Sexo } \\
\cline { 2 - 5 } & Tese & Dissertação & Masculino & Feminino \\
\hline Ação afirmativa & 1 & $\mathrm{x}$ & 1 & $\mathrm{x}$ \\
\hline Cor/raça & $\mathrm{x}$ & 1 & 1 & $\mathrm{x}$ \\
\hline
\end{tabular}




\begin{tabular}{l|c|c|c|c}
\multirow{2}{*}{ Subtemas } & \multicolumn{2}{|c|}{ Natureza do trabalho } & \multicolumn{2}{c}{ Sexo } \\
\cline { 2 - 5 } & Tese & Dissertação & Masculino & Feminino \\
\hline Educaçáo superior & $\mathrm{x}$ & 1 & $\mathrm{x}$ & 1 \\
\hline Infância & $\mathrm{x}$ & 3 & $\mathrm{x}$ & 3 \\
\hline Literatura & 1 & 2 & 1 & 2 \\
\hline Mercado de trabalho & $\mathrm{x}$ & 1 & $\mathrm{x}$ & 1 \\
\hline Total & 2 & 8 & 3 & 7 \\
\hline
\end{tabular}

Fonte: Banco de dados da pesquisa

Nesse corpus documental de estudos sobre relaçôes raciais defendidos pelo NEGRI, percebe-se pelas Tabelas 1,2 , e 3, a predominância das mulheres $(70,0 \%)$, das quais $60,0 \%$ se encontram no mestrado. Nos doutorados, observa-se mais homens ( 2 para 1 ), o que pode indicar que a área de Psicologia, especialmente voltada a subtemas como educação, está ligada ao sexo feminino no plano dos discentes: se em virtude da simples maioria numérica das mulheres ou se por um interesse de gênero, não há elementos para afirmá-los.

A Tabela 3, elaborada a partir de elementos apresentados nos textos, mostra que um estudo produzido e defendido sobre relaçóes raciais, nesse corpus, não se debruça diretamente da área da educaçáo, mas sim do mercado de trabalho. Pode-se observar, também, que os demais estudos estâo relacionados à área da educaçáo. Em um primeiro olhar, isto ocorre em razão do NEGRI ter uma abrangência facilitadora do diálogo com a área da educação. Outra informação é que a última tese defendida está ligada a programas de ação afirmativa.

Tabela 4 - Defesas

\begin{tabular}{c|c|c|c} 
Ano & Mestrado & Doutorado & Total \\
\hline 1992 & 2 & $\mathrm{x}$ & 2 \\
\hline 1993 & 1 & $\mathrm{x}$ & 1 \\
\hline 1994 & 1 & $\mathrm{x}$ & 1 \\
\hline 1995 & $\mathrm{x}$ & 1 & 1 \\
\hline 1996 & $\mathrm{x}$ & $\mathrm{x}$ & $\mathrm{x}$ \\
\hline
\end{tabular}




\begin{tabular}{|c|c|c|c|}
\hline 1997 & $\mathrm{x}$ & $\mathrm{x}$ & $\mathrm{x}$ \\
\hline 1998 & $\mathrm{x}$ & $\mathrm{x}$ & $\mathrm{x}$ \\
\hline 1999 & 1 & $\mathrm{x}$ & 1 \\
\hline 2000 & $\mathrm{x}$ & $\mathrm{x}$ & $\mathrm{x}$ \\
\hline 2001 & $\mathrm{x}$ & $\mathrm{x}$ & $\mathrm{x}$ \\
\hline 2002 & $\mathrm{x}$ & $\mathrm{x}$ & $x$ \\
\hline 2003 & $\mathrm{x}$ & $\mathrm{x}$ & $\mathrm{x}$ \\
\hline 2004 & $\mathrm{x}$ & $\mathrm{x}$ & $\mathrm{x}$ \\
\hline 2005 & 1 & 1 & 2 \\
\hline 2006 & $\mathrm{x}$ & $\mathrm{x}$ & $\mathrm{x}$ \\
\hline 2007 & $\mathrm{x}$ & $\mathrm{x}$ & $\mathrm{x}$ \\
\hline 2008 & $\mathrm{x}$ & $\mathrm{x}$ & $\mathrm{x}$ \\
\hline 2009 & $\mathrm{x}$ & $\mathrm{x}$ & $\mathrm{x}$ \\
\hline 2010 & $\mathrm{x}$ & 1 & 1 \\
\hline 2011 & $\mathrm{x}$ & $\mathrm{x}$ & $\mathrm{x}$ \\
\hline 2012 & $\mathrm{x}$ & $\mathrm{x}$ & $\mathrm{x}$ \\
\hline 2013 & $x$ & $\mathrm{x}$ & $\mathrm{x}$ \\
\hline 2014 & 1 & $\mathrm{x}$ & $\mathrm{x}$ \\
\hline $\begin{array}{c}\text { Percentual por } \\
\text { nível }\end{array}$ & $70,0 \%$ & $30,0 \%$ & $100 \%$ \\
\hline
\end{tabular}

Fonte: Banco de teses da PUC-SP

De modo geral, constata-se pela Tabela 4, uma irregularidade quanto à quantidade de produçóes por ano ao longo do período examinado (1992-2014). O período investigado inicia-se com cinco produçóes no período entre (1992-1995). Também é observado um período de 15 anos sem produçôes defendidas, dessa natureza, porém não sequenciais e divididos em quatro três períodos ${ }^{8}$ : (1996-1998) (2000-2004) e (2006-2009), (2011-2013), embora tenha ocorrido defesas de teses e dissertaçóes de temas relacionados às desigualdades de gênero e idade.

8 Vale ressaltar, que nos períodos em que não foram defendidos estudos sobre o tema das relaçốes raciais, encontramos 20 produçôes acadêmicas (teses e dissertaçóes) defendidas: 12 (idade) e 8 (gênero). 


\section{Quadro 2 - Professores participantes de bancas de defesas (teses e dissertaçóes) sobre relaçóes raciais no NEGRI}

\begin{tabular}{|c|c|c|c|}
\hline Professores & Participações & Área de atuaçáo & Universidade \\
\hline Ana Merces Bahia Bock & 1 & Psicologia & PUC-SP \\
\hline Antonio Chizzotti & 1 & Educação & PUC-SP \\
\hline Antonio da Costa Ciampa & 4 & Psicologia & PUC-SP \\
\hline Bader Buriham Sawaia & 3 & Psicologia & PUC-SP \\
\hline $\begin{array}{l}\text { Circe Maria Fernandes } \\
\text { Bittercourt }\end{array}$ & 1 & Educação & PUC-SP \\
\hline Fúlvia Rosemberg & 9 & Psicologia & PUC-SP \\
\hline Iray Carone & 1 & Psicologia & USP-SP \\
\hline Kabengele Munanga & 2 & Antropologia & USP-SP \\
\hline $\begin{array}{l}\text { Luiz Alberto Oliveira } \\
\text { Gonçalves }\end{array}$ & 2 & Educação & UFMG-MG \\
\hline Maria do Carmo Guedes & 1 & Psicologia & PUC-SP \\
\hline $\begin{array}{l}\text { Maria Laura Puglisi Barbosa } \\
\text { Franco }\end{array}$ & 1 & Educação & PUC-SP \\
\hline $\begin{array}{l}\text { Maria Letícia Barros Pedroso } \\
\text { Nascimento }\end{array}$ & 1 & Educação & USP-SP \\
\hline Mere Abramowicz & 1 & Educação & PUC-SP \\
\hline Odair Furtado & 1 & Psicologia & PUC-SP \\
\hline $\begin{array}{l}\text { Petronilia Beatriz Gonçalves } \\
\text { da Silva }\end{array}$ & 1 & Educação & UFScar-SP \\
\hline Rachel de Oliveira & 1 & Educação & $\begin{array}{c}\text { Universidade } \\
\text { Estadual de Santa } \\
\text { Cruz-BA }\end{array}$ \\
\hline Regina Pahim Pinto & 4 & Educação & $\begin{array}{c}\text { Fundação Carlos } \\
\text { Chagas-SP } \\
\end{array}$ \\
\hline Sigmar Malvezzi & 1 & Psicologia & PUC-SP \\
\hline
\end{tabular}

Fonte: Banco de dados da pesquisa - elaborado pelo autor * Vale ressaltar que foi considerado para este estudo a filiação universitária do professor componente da banca examinadora na época da defesa. 
$\mathrm{Na}$ análise do Quadro 2, mostra que existe uma diversidade de professores participantes dessas bancas (18). Apenas seis (6) professores, participaram em mais de uma defesa. Este quadro possibilita perceber também, que o número de mulheres participantes (12) permanece bem acima do número de homens participantes (6). Outra informaçấo que se pode observar é a de que oito (8) dos professores atuavam na área da Psicologia e oito (8) na área da Educação e apenas um (1) atuava na área da Antropologia. Vale destacar que são 12 o número de avaliadoras do sexo feminino.

$\mathrm{Na}$ análise em números, no que se refere às universidades de origem dos professores participantes das defesas de teses e dissertaçóes, observamos que 11 professores pertenciam ao grupo de docentes da PUC-SP, outros três (3) professores pertenciam a grupo de docentes da USP, além de quatro (4) outros docentes que pertenciam a Instituiçôes diversas (FCC-UFScarUFMG-UESC). Outra informação é que, apenas dois (2) professores não eram do Estado de São Paulo (MG- BA).

Tabela 6 Agências financiadoras por sexo (mestrado)

\begin{tabular}{l|c|c|c|c|c|c|c|c|c|c}
$\begin{array}{l}\text { Agência } \\
\text { Financiadora }\end{array}$ & \multicolumn{2}{|c|}{ CAPES } & \multicolumn{2}{c|}{ CNPq } & \multicolumn{2}{c|}{ FAPESP } & \multicolumn{2}{c|}{ Outras } & \multicolumn{2}{c}{$\begin{array}{c}\text { Sem } \\
\text { indicaçáo }\end{array}$} \\
\hline Sexo & $\mathrm{M}$ & $\mathrm{F}$ & $\mathrm{M}$ & $\mathrm{F}$ & $\mathrm{M}$ & $\mathrm{F}$ & $\mathrm{M}$ & $\mathrm{F}$ & $\mathrm{M}$ & $\mathrm{F}$ \\
\hline $\begin{array}{l}\text { Total por } \\
\text { sexo/agência }\end{array}$ & $\mathrm{x}$ & 2 & & 3 & $\mathrm{x}$ & $\mathrm{x}$ & 1 & $\mathrm{x}$ & $\mathrm{x}$ & 1 \\
\hline
\end{tabular}

Fonte: Plataforma Lattes/Currículo Lattes

Tabela 7 Agências financiadoras por sexo (doutorado)

\begin{tabular}{l|c|c|c|c|c|c|c|c|c|c}
\hline $\begin{array}{l}\text { Agência } \\
\text { Financiadora }\end{array}$ & \multicolumn{2}{|c|}{ Capes } & \multicolumn{2}{c|}{ CNPq } & \multicolumn{2}{c|}{ Fapesp } & \multicolumn{2}{c|}{ Outras } & \multicolumn{2}{c}{$\begin{array}{c}\text { Sem } \\
\text { indicaçáo }\end{array}$} \\
\hline Sexo & M & F & M & F & M & F & M & F & M & F \\
\hline $\begin{array}{l}\text { Total por } \\
\text { sexo/agência }\end{array}$ & 2 & $\mathrm{x}$ & $\mathrm{x}$ & $\mathrm{x}$ & $\mathrm{x}$ & $\mathrm{x}$ & $\mathrm{x}$ & $\mathrm{x}$ & $\mathrm{x}$ & 1 \\
\hline
\end{tabular}

Fonte: Plataforma Lattes/Currículo Lattes 
As Tabelas 6 e 7, construídas a partir de informaçóes extraídas de resumos publicados no website da Capes e do currículo lattes dos pesquisadores, mostra que das 10 pesquisas consideradas neste corpus, oito (8) tiveram financiamentos de agências de fomento. Duas não pudemos precisar (não foi localizado na Plataforma Lattes o currículo do pesquisador). O CNPq foi responsável por cinco (5) financiamentos, a CAPES por quatro (4) financiamentos e uma de outra natureza (Fundação Aniela e Tadeusz Ginsberg). Vale destacar que os dois (2) estudos do doutorado tiveram apoio da CAPES. Dos mestrados, três estudos foram financiados pelo CNPq, todos do sexo feminino.

\section{Analise qualitativa}

As tabelas anteriormente citadas foram construídas a partir de informaçóes coletadas dos resumos do website da Capes, das teses e dissertaçóes e do currículo lattes, sobre os quais já se pode apontar algumas conclusóes analíticas de base quantitativa. A mais importante delas diz mais da pesquisa e dos pesquisadores acadêmicos que da própria temática em pauta, ao demonstrar que os estudos sobre relaçôes raciais são feitos na grande maioria em mestrados, com financiamento e por mulheres (discentes) na área da Educação. Além de serem orientados por mulheres e avaliados por mulheres, em grande maioria, da área da Educação, do Estado de São Paulo e de instituições particulares.

Ao considerar-se o recorte do tema das relaçôes raciais ${ }^{9}$ dentro do NEGRI $^{10}$, verifica-se, que esse tema representa apenas $16,6 \%$ da produção acadêmica do NEGRI na PUC-SP, no período (1987-2014), sendo três teses e sete dissertaçóes. A nosso ver, trata-se de uma questão importante. Se

\footnotetext{
9 Não foi possível criar a tabela cor/raça dos pesquisadores, muito embora a PUC-SP tenha introduzido no formulário de inscrição de seus candidatos aos Programas de Pós-graduação o pertencimento de identificação étnico-racial a partir do ano de 2005.

10 Fonte: Currículo Lattes, Fúlvia Rosemberg, 2014.
} 
em virtude da ausência de pós-granduandos negros ou se por um interesse para outros temas, como gênero e idade, não há elementos para afirmá-lo.

Assim, para acrescentar refinamento à análise dos dados quantificáveis, adotou-se em seguida uma abordagem qualitativa, construída a partir da identificação de outros elementos presentes nas teses e dissertaçóes (palavras-chave, subtema, objeto de estudo) Assim, é possível apreender como os pesquisadores desses estudos sobre relaçóes raciais se aproximaram do tema, como o problematizaram e como enfrentaram os problemas levantados e a que conclusões chegaram. Para essa análise, serão considerados os 10 estudos sobre relaçóes raciais produzidos no NEGRI e que resultaram no quadro 3, o qual mapeia: autor, ano, natureza do trabalho, palavras-chave, período abrangido pela pesquisa, questão e objeto de pesquisa.

Quadro 3 Mapeamento do corpus documental

\begin{tabular}{l|l|l|l|c|l|l} 
Autor/a & Ano & $\begin{array}{l}\text { Na tu reza } \\
\text { do trabalho }\end{array}$ & $\begin{array}{l}\text { Palavras- } \\
\text { chave } \\
\text { abrangido } \\
\text { pela } \\
\text { pesquisa }\end{array}$ & $\begin{array}{l}\text { Questáo ou } \\
\text { subtema }\end{array}$ & $\begin{array}{l}\text { Objeto de } \\
\text { estudo }\end{array}$ \\
$\begin{array}{l}\text { Maria } \\
\text { Aparecida } \\
\text { Silva } \\
\text { Bento }\end{array}$ & 1992 & Mestrado & $\begin{array}{l}\text { Discrimi- } \\
\text { naçáo racial } \\
\text { no trabalho; } \\
\text { resistência } \\
\text { negra no } \\
\text { trabalho; } \\
\text { identidade. }\end{array}$ & $\begin{array}{l}\text { Anos } \\
1990\end{array}$ & $\begin{array}{l}\text { Discrimi- } \\
\text { naçáo racial } \\
\text { e resistência } \\
\text { na voz dos } \\
\text { trabalhado- } \\
\text { res negros }\end{array}$ & $\begin{array}{l}\text { Adulto } \\
\text { em } \\
\text { instituição }\end{array}$ \\
\hline $\begin{array}{l}\text { Rachel de } \\
\text { Oliveira }\end{array}$ & 1992 & Mestrado & $\begin{array}{l}\text { Negro; crian- } \\
\text { ça; educaçáo. }\end{array}$ & $\begin{array}{l}\text { Anos } \\
1980\end{array}$ & $\begin{array}{l}\text { Relaçóes } \\
\text { raciais na } \\
\text { escola: uma } \\
\text { experiência } \\
\text { de interven- } \\
\text { ção }\end{array}$ & $\begin{array}{l}\text { Infância } \\
\text { em } \\
\text { instituição }\end{array}$ \\
\hline
\end{tabular}


Revista Itinerarius Reflectionis - UFG

\begin{tabular}{|c|c|c|c|c|c|c|}
\hline $\begin{array}{l}\text { Neiva de } \\
\text { Oliveira } \\
\text { Moro }\end{array}$ & 1993 & Mestrado & $\begin{array}{l}\text { Relaçôes ra- } \\
\text { ciais; escolha } \\
\text { profissional; } \\
\text { educação. }\end{array}$ & $\begin{array}{l}\text { Anos } \\
1990\end{array}$ & $\begin{array}{l}\text { Estudantes } \\
\text { universitá- } \\
\text { rios: } \\
\text { carreira e } \\
\text { raça }\end{array}$ & $\begin{array}{l}\text { Adulto } \\
\text { em } \\
\text { instituição }\end{array}$ \\
\hline $\begin{array}{l}\text { Eliana } \\
\text { Oliveira }\end{array}$ & 1994 & Mestrado & $\begin{array}{l}\text { Creche; rela- } \\
\text { çóes raciais. }\end{array}$ & $\begin{array}{l}\text { Anos } \\
1990\end{array}$ & $\begin{array}{l}\text { Relações } \\
\text { raciais de } \\
\text { crianças na } \\
\text { creche }\end{array}$ & $\begin{array}{l}\text { Infância } \\
\text { em } \\
\text { instituição }\end{array}$ \\
\hline $\begin{array}{l}\text { Edith } \\
\text { Piza }\end{array}$ & 1995 & Doutorado & $\begin{array}{l}\text { Estereótipos; } \\
\text { relaçôes } \\
\text { de gênero; } \\
\text { literatura. }\end{array}$ & $\begin{array}{l}1970- \\
1980\end{array}$ & $\begin{array}{l}\text { Literatura } \\
\text { infanto-ju- } \\
\text { venil: } \\
\text { Estereóti- } \\
\text { pos. }\end{array}$ & $\begin{array}{l}\text { Mercado } \\
\text { editorial e } \\
\text { educação }\end{array}$ \\
\hline $\begin{array}{l}\text { Chirley } \\
\text { Bazilli }\end{array}$ & 1999 & Mestrado & $\begin{array}{l}\text { Personagens } \\
\text { negros; } \\
\text { literatura } \\
\text { infanto-ju- } \\
\text { venil. }\end{array}$ & $\begin{array}{l}1975- \\
1994\end{array}$ & $\begin{array}{l}\text { Literatura } \\
\text { infanto-ju- } \\
\text { venil: } \\
\text { discrimi- } \\
\text { nação de } \\
\text { personagens } \\
\text { negros. }\end{array}$ & $\begin{array}{l}\text { Mercado } \\
\text { editorial e } \\
\text { educaçáo }\end{array}$ \\
\hline $\begin{array}{l}\text { Edmar } \\
\text { José } \\
\text { Rocha }\end{array}$ & 2005 & Mestrado & $\begin{array}{l}\text { Criança; } \\
\text { classificação } \\
\text { racial; cor; } \\
\text { raça. }\end{array}$ & $\begin{array}{l}2003- \\
2005\end{array}$ & $\begin{array}{l}\text { Crianças e } \\
\text { adolescentes } \\
\text { de escola } \\
\text { pública; } \\
\text { autoclassifi- } \\
\text { cação racial. }\end{array}$ & $\begin{array}{l}\text { Infância } \\
\text { em } \\
\text { instituição }\end{array}$ \\
\hline $\begin{array}{l}\text { Paulo } \\
\text { Vinícius } \\
\text { Baptista } \\
\text { da Silva }\end{array}$ & 2005 & Doutorado & $\begin{array}{l}\text { Relaçóes } \\
\text { raciais, livros } \\
\text { didáticos, dis- } \\
\text { curso racista, } \\
\text { negros. }\end{array}$ & $\begin{array}{l}1975- \\
1994\end{array}$ & $\begin{array}{l}\text { Relaçôes } \\
\text { raciais em } \\
\text { livro didá- } \\
\text { tico. }\end{array}$ & $\begin{array}{l}\text { Mercado } \\
\text { editorial e } \\
\text { educaçáa }\end{array}$ \\
\hline
\end{tabular}




\begin{tabular}{|c|c|c|c|c|c|c|}
\hline $\begin{array}{l}\text { Antônio } \\
\text { Honório } \\
\text { Ferreira }\end{array}$ & 2010 & Doutorado & $\begin{array}{l}\text { Ação afirma- } \\
\text { tiva, negro, } \\
\text { análise de } \\
\text { conteúdo, } \\
\text { Programa IFP }\end{array}$ & 2007 & $\begin{array}{l}\text { Discursos } \\
\text { étnico- } \\
\text { raciais } \\
\text { proferidos } \\
\text { por } \\
\text { candidatos } \\
\text { (as) a } \\
\text { programa } \\
\text { de ação } \\
\text { afirmativa. }\end{array}$ & $\begin{array}{l}\text { Adulto } \\
\text { em } \\
\text { instituição }\end{array}$ \\
\hline $\begin{array}{l}\text { Marta } \\
\text { Lucia da } \\
\text { Silva }\end{array}$ & 2014 & Mestrado & $\begin{array}{l}\text { Bebê, creche, } \\
\text { educação } \\
\text { infantil; } \\
\text { relaçóes ra- } \\
\text { ciais; estudos } \\
\text { sociais } \\
\text { da infância. }\end{array}$ & $\begin{array}{l}2011- \\
2014\end{array}$ & $\begin{array}{l}\text { Discursos } \\
\text { de mães } \\
\text { negras sobre } \\
\text { educação e } \\
\text { cuidado de } \\
\text { crianças de } \\
\text { até } 3 \text { anos } \\
\text { de idade }\end{array}$ & $\begin{array}{l}\text { Infância } \\
\text { em } \\
\text { instituiçáo }\end{array}$ \\
\hline
\end{tabular}

\section{O campo de referência}

Por um lado, as palavras-chave (coluna 4) do quadro 3 permitem que se faça uma análise do campo percorrido pelos respectivos autores, nos quais encontra-se quadros autoexplicativos de forma que expóem a opção de alguns pesquisadores da amostra (MORO, 1993; OLIVEIRA, 1994; SILVA, 2005) em desenvolver suas investigações, tendo o tema das relaçōes raciais como chave interpretativa. Por outro, é possível observar a incidência de termos ligados à pertença racial (negro, cor, raça). No NEGRI, entendemos o conceito de raça como construção social. Na esteira de Guimarães (2003), considera-se que o conceito analítico de raça como construção social é fundamental para a compreensão das desigualdades sociais, estruturais e simbólicas, observadas em nossa sociedade. 
Há também termos ligados ao racismo (personagens negros, discursos racistas). Nesse sentido, essas pesquisas comungam com as reflexóes de Essed, 1991, Rosemberg, 2003 e Guimarães, 2005 sobre as desigualdades observadas entre brancos e negros no acesso a bens materiais e simbólicos, por causa do racismo constitutivo de nossa sociedade. Encontra-se outros termos relacionados à Educação (creche, educação, livros didáticos, crianças), o que pode significar que os autores procuram dar conta da temática das relaçóes raciais por intermédio do aluno, do professor ou da instituição.

A investigação de Bento (2010) teve enfoque no mercado de trabalho (discriminação racial no trabalho, resistência negra no trabalho), que, de certo modo, faz uma conexão com a investigação de Moro (1993), ao pesquisar carreiras educacionais, e de Ferreira (2010) que investigou sobre candidatos a programas de ação afirmativa. Esses pesquisadores, cada um ao seu modo, contribuíram para a formação do campo de estudos das relaçóes raciais e da inserção acadêmica e/ou profissional. Nas palavras-chave também aparecem termos relacionados à identidade e gênero, categorias que já constituem campos próprios de estudos. Enfim, nesse corpus, as palavras-chave revelam o campo percorrido pelos pesquisadores entre 1992 e 2010 e, por isso, indicam às vezes uma sobreposição de temas (PIZA, 1995; BAZILLI, 1999).

\section{O período abrangido}

Outro elemento destacado no Quadro 3 - o período compreendido pela pesquisa (coluna 5) - permite o reconhecimento do tema das relaçóes raciais pela via do recorte cronológico trazido pelos autores em seus textos, nota-se que há estudos que abrangem a década de 1970 e períodos recente nas décadas (1980, 1990, 2000),bem como períodos até 2014. Observa-se também, uma concentraçáo de estudos sobre os anos 1990. 
Observa-se no corpus documental um conjunto de trabalhos relacionados à literatura, a partir dos anos 1970 até meados dos anos 1990, época de grande efervescência política e cultural, numa transição de transformaçóes econômicas e sociais. Não é demais lembrar que os pesquisadores do NEGRI entendem livros didáticos e a literatura infanto-juvenil como produçôes midiáticas. Por exemplo, os livros didáticos exercem não só o papel de reprodução, mas também de produção da ideologia de gênero, raça e idade. As instituiçóes de educação fazem a mediação criança-adulto, mantendo relaçôes de dominação e dependência da criança, de adolescentes em relação ao adulto; deles é exigido que se adaptem ao mundo adulto.

A década de 2000 também foi marcada por importantes mudanças em termos de políticas públicas, políticas educacionais, que, de certo modo, interferiram nas produçóes do NEGRI: Censo Escolar 2005 e Programas de Ações Afirmativas. Para tanto, destaca-se a pesquisa realizada por Rocha (2005); nesse período foi introduzido no país pela primeira vez, o quesito cor/raça no Censo Escolar 2005, organizado pelo Mec/Inep. Mesmo período em que a PUC-SP introduz no formulário de inscrição de seus candidatos aos Programas de Pós-Graduação o pertencimento de identificação étnicoracial. Uma das dificuldades mencionadas pelo autor para realizar a pesquisa na época foi a carência de reflexão disponível sobre cor, enquanto conceito na discussão acadêmica.

Outra investigação que merece destaque éa pesquisa de Ferreira (2010). $\mathrm{O}$ período em que essa tese foi desenvolvida, coincidiu com a aprovação do Estatuto da Igualdade Racial, em defesa dos que sofrem preconceito ou discriminação em função de sua etnia, raça e/ou cor, aprovado em junho de 2010, no Senado e sancionada como lei, sob número 12.288 no dia 20/07/2010, pelo Presidente Luís Inácio Lula da Silva, com várias alterações em relação ao texto original, mas prevendo a adoção de programas de ação afirmativa. Vale ressaltar que o tema das açóes afirmativas, foi amplamente discutido por Ferreira (2010). 
O autor, em sua investigação na perspectiva do NEGRI, propôs interpretaçóes a discursos étnico-raciais proferidos no contexto do Programa Internacional de Bolsas de Pós-graduação da Fundação Ford (Programa IFP), destinado, entre outros segmentos sociais, a negros e indígenas.

Por sua vez, quando o tema é infância (creche) e relaçóes raciais, apreendemos através da dissertação de Silva (2014), que esse tema mostra discursos diferenciados: reconhecimento do racismo e desigualdades entre negros e não negros, bem como que na sociedade brasileira as reivindicaçóes do movimento negro são mais direcionadas ao mundo do adulto do que ao bebê.

Cruzando dois critérios empregados em nossa análise (objeto de estudo e periodização), percebe-se que o interesse pela "instituição" parecia estar absorvendo o foco de atenção dos pesquisadores (BENTO,1992; OLIVEIRA,1992; MORO, 1993; OLIVEIRA, 1994; ROCHA,2005; FERREIRA, 2010, SILVA,2014). O mercado editorial brasileiro ligados ao sistema educacional, também foi foco de atenção de pesquisadores (PIZA, 1995; BAZILLI, 1999; SILVA, 2005).

Constatou-se também, que apenas a investigação de Bento (1992), teve seu olhar para fora dos muros escolares, o mercado de trabalho. Esse estudo pode ter sido inspirado não só para discutir a discriminação do negro no mercado do trabalho, mas também para discutir a crise e as transformaçóes ocorridas nesse mercado, especialmente o assalariado a partir dos anos 1990. A década de 1990 também foi marcada pela promulgação do Estatuto da Criança e do Adolescente. Essa legislação levou a questionamentos em torno do lugar da esfera do trabalho na vida de crianças, adolescentes e jovens, de suas experiências concretas nesse espaço, diante de um cenário de desemprego e precarização das relaçóes trabalhistas e das açóes públicas implementadas por diferentes atores sociais para lidar com essa conjuntura.

De modo geral, observa-se que os pesquisadores do NEGRI, sobre a tematica das relaçóes raciais voltaram-se para o extraordinário, ou seja, 
para períodos de maior efervescência e abundância, acompanharam o momento histórico e os debates que estavam e estão ocorrendo (creche-açôes afirmativas na sociedade brasileira, em suas pesquisas.

Pensamos ser importante, também, que o pesquisador volte suas lentes para períodos rotineiros de calmaria, nos quais o negro passa despercebido. Ademais, a abordagem da temática das relaçóes raciais pelo critério do período abrangido revela-se insuficiente para o alargamento do campo. Há subtemas voltados à população negra que não são abordados nas pesquisas analisadas, como saúde da população negra, comunidades quilombolas, juventude negra, elite negra, entre outros. Isso ocorre se em virtude da falta de interesse dos pesquisadores, ou se por uma ausência de pesquisadores para investigar os temas, não há elementos para afirmá-lo.

\section{O objeto em enfoque}

O terceiro critério de análise compreende as duas últimas colunas do quadro 3: questão e objeto. A partir desses elementos, construíram-se três grandes conjuntos. O primeiro deles - inclui os textos em que o tema das relaçóes raciais aparece como discursos (SILVA, 2005; FERREIRA, 2010; SILVA, 2010). No NEGRI, utilizamos o conceito de discurso como tem sido amplamente empregado na teoria e análise social, como instâncias de comunicação usuais, que são constitutivas e constituídas nos diferentes modos de estruturação das práticas sociais. Para Thompon (2011), discursos se manifestam em modos particulares de uso das formas simbólicas, em particular da linguagem, e não apenas refletem as relaçóes sociais, mas participam de sua construção, "formas simbólicas são construções significativas que exigem uma interpretação; elas são ações, falas, textos que, por serem construçôes significativas, podem ser compreendidas" (THOMPSON, 2011, p.357). 
Ademais, no NEGRI, temos desenvolvido outras pesquisas que analisam discursos proferidos por adultos e destinados a crianças, adolescentes e adultos, cujo tema se refere à infância, em instituiçôes e diversos veículos de comunicação.

No segundo conjunto encontram-se estudos que abordam o tema das relaçóes raciais no âmbito da literatura, literatura infanto-juvenil e do livro didático (PIZA, 1995; BAZILLI, 1999; SILVA, 2005). Na perspectiva desses autores, a difusão de um imaginário negativo em relação ao negro e dos significados positivos em relação aos brancos é estratégia de discurso racista observada como forma de discriminação no interior das escolas, via livros didáticos e literatura infanto-juvenil. O discurso é atuante para a produção e reprodução de desigualdades raciais.

No terceiro conjunto encontram-se os estudos que, em nosso entendimento, enfrentam a questão da idade, como objeto de pesquisa ou como um tema a ser problematizado (OLIVEIRA, 1994, SILVA, 2014). Essas pesquisas têm contribuído para a constituição de um campo de estudos que visa tirar a pequena infância (bebê) da invisibilidade. Além disso, colaboram com a construçáo de uma concepção de cuidado e educação de bebês que concebe a creche de qualidade como direito das crianças de 0 a 3 anos. Por conseguinte, temos no NEGRI problematizado a construçáo da agenda de políticas públicas para a infância brasileira contemporânea, nomeadamente aposiçẫo subalterna destinada à pequena infância nas políticas educacionais.

Por último apresenta-se outro conjunto (OLIVEIRA, 1992; MORO, 1993; ROCHA, 2005). Esses estudos caracterizam-se por conseguir explicar os atores sociais em um determinado contexto da educaçáo brasileira, a partir de um conjunto de variáveis. A grande força desse terceiro conjunto de estudos foi a possibilidade de dar voz a diferentes atores sociais de forma explicita ou nem tanto. Oliveira (1994) procurou deflagrar dentro das escolas o processo de debate sobre a situação socioeconômica e política do negro. Moro (1993), por sua vez, analisou a inserção de estudantes na educação superior, ocupando-se da investigação de suas carreiras 
educacionais, comparando-as às dos brancos. Rocha (2005), ao dar voz a crianças e adolescentes, procura associar um objetivo político ao plano de conhecimento, acolhendo os novos paradigmas dos estudos sobre infância. Neste sentido, entende que crianças e adolescentes são atores sociais e, portanto, têm o direito de expressar sua pertença racial.

\section{Referências}

BARDIN, Laurence. Análise de conteúdo. Tradução de Luís Antero Reto e Augusto Pinheiro. Lisboa: Capa de Edições 70, 1977-2011.

BAZILLI, Chirley. Discriminação contra personagens negros na literatura infanto-juvenil brasileira contemporânea. Dissertação (Mestrado em Psicologia Social) - Pontifícia Universidade Católica de São Paulo, São Paulo, 1999.

BENTO, Maria Aparecida Silva. Resgatando a minha bisavó: discriminação racial no trabalho e resistência na voz dos trabalhadores negros. Dissertação (Mestrado em Psicologia Social) - Pontifícia Universidade Católica de São Paulo, São Paulo, 1992.

BRASIL. Lei no 13.005, de 25 junho de 2014, aprova o Plano Nacional de Educação - PNE (2011-2020). Aprova o Plano Nacional de Educação PNE e dá outras providências. Disponível em : http://www2.camara.leg.br/ legin/fed/lei/2014/lei-13005-25-junho-2014-778970-publicacaooriginal144468-pl.html.

BRASIL. Ministério da Educação. Plano Nacional de Pós-graduação (PNPG) 2011-2020. Brasília, dez. 2010.

BROOKE, Nigel. Perspectiva dos estudos negros e educação. In: OLIVEIRA, Iolanda de (org.). Relaçôes raciais e educação: Temas contemporâneos. Cadernos Penseb, Niterói, Editora da UFF, n. 5, p.151-158, 2002.

CARVALHO, Marília Pinto de. O fracasso escolar de meninos e meninas: articulaçôes entre gênero e cor/raça. Cadernos Pagu, Campinas, n.22, p. 247-290, jun. 2004. 
ESSED, Philomena. Understanding everyday racism: interdisciplinary theory. Londres: Sage, 1991.

FERREIRA, Antonio Honório. Discursos étnico-raciais proferidos por candidatos/as a programa de ação afirmativa. Tese (Doutorado em Psicologia Social)- Pontifícia Universidade Católica de São Paulo, São Paulo, 2010.

GUIMARĀES, Antônio Sérgio Alfredo. Racismo e anti-racismo no Brasil. São Paulo: Editora 34, 2005.

34, 2002.

. Classes, raças e democracia. São Paulo: Editora

GUIMARÁES, Reinaldo; LOURENÇO, Ricardo; COSAC, Silvana. O perfil dos doutores ativos em pesquisa no Brasil. Parcerias Estratégicas, Brasília, n. 13, p. 122-150, dez. 2001.

MORO, Neiva de Oliveira. Um estudo sobre o universitário do anual de 1990 da Universidade Estadual de Ponta Grossa: carreiras educacionais e raça. Dissertação (Mestrado em Psicologia Social) - Pontifícia Universidade Católica de São Paulo, São Paulo, 1993.

OLIVEIRA, Eliana. Relaçôes raciais nas creches do município de São Paulo. Dissertação (Mestrado em Educação) - Pontifícia Universidade Católica de São Paulo, São Paulo, 1994.

OLIVEIRA, Rachel de. Relaçôes raciais na escola: uma experiência de intervenção. Dissertação (Mestrado em Educação) - Pontifícia Universidade Católica de São Paulo, São Paulo, 1992.

PAIXÃO, Marcelo. (Org.). Relatório anual das desigualdades raciais no Brasil: 2009-2010. Rio de Janeiro, Universidade Estadual do Rio de Janeiro, Rio de Janeiro, 2010.

PETRUCCELLI, J. L., SABOIA, A. L. (Org). Características étnico-raciais da população: classificaçôes e identidades. R.J. IBGE, 2013. 
PIZA, Edith Pompeu. O caminho das águas: estereótipo de personagens femininas negras nas obras femininas de escritoras brancas. Tese (Doutorado em Psicologia Social) - Pontifícia Universidade Católica de São Paulo, São Paulo, 1995.

RIBEIRO, Maria Silvia. Relaçôes de gênero e de idade em discursos sobre sexualidade veiculados em livros didáticos brasileiros de Ciências Naturais. Dissertação (Mestrado em Psicologia Social) - Pontifícia Universidade Católica de São Paulo, São Paulo, 2013.

ROCHA, Edmar José da. Autodeclaração de cor elou raça entre alunos(as) paulistanos(as) do ensino fundamental e médio: um estudo exploratório. Dissertação (Mestrado em Psicologia Social) - Pontifícia Universidade Católica de São Paulo, São Paulo, 2005.

ROSEMBERG, Fúlvia. Politicas educacionais e gênero: um balanço dos anos 1990. Cadernos Pagu, Campinas, n. 16, p. 151-198, 2001.

ROSEMBERG, Fúlvia; BAZILLI, Chirley; SILVA, Paulo Vinicius Baptista da. Racismo em livros didáticos brasileiros e seu combate: uma revisão da literatura. Educação e Pesquisa, São Paulo, v. 29, n. 1, p. 125-146, jan/jun 2003.

SILVA, Marcos Antonio Batista da. Trajetória de mestres(as) negros(as) Paulistas: barreiras e impulsos. Projeto de tese de doutorado (Psicologia Social) - Pontifícia Universidade Católica de São Paulo, São Paulo, 2012.

SILVA, Marta Lucia. Discursos de mães negras sobre educação e cuidado de crianças de até três anos de idade. Dissertação (Mestrado em Psicologia Social) - Pontifícia Universidade Católica de São Paulo, São Paulo, 2014.

SILVA, Paulo Vinícius Baptista. Relaçôes raciais em livros didáticos de Língua Portuguesa. Tese (Doutorado em Psicologia Social) - Pontifícia Universidade Católica de São Paulo, São Paulo, 2005.

THOMPSON, John Brookshire. Ideologia e cultura moderna: teoria social crítica na era dos meios de comunicação de massa. Petrópolis, RJ: Vozes, 2011. 
VELHO, Léa. O papel da formação de pesquisadores no sistema de inovação. Ciência e cultura, São Paulo, v. 59, n. 4, p. 23-28, 2007.

VELLOSO, Jacques. Mestres e doutores no pais: destinos profissionais e politicas de pós-graduação. In: Caderno de Pesquisa. São Paulo: Fundação Carlos Chagas, v. 34, n. 123 set/dez 2004, p. 583-611. 
